\title{
Dynamic Feedback Analysis of Incentive Factors for Building Energy Conservation Reconstruction in China
}

\author{
Handing Guo \\ Tianjin Chengjian University \\ Wanzhen Qiao ( $\sim$ qiuchaoyue16@163.com ) \\ Tianjin Chengjian University \\ Xing Wang \\ Tianjin Chengjian University
}

\section{Research Article}

Keywords: Sustainable buildings, energy efficiency, government policy, building energy saving, incentive, green buildings Received: March 20,2021; Accepted: date; Published: date

Posted Date: April 13th, 2021

DOl: https://doi.org/10.21203/rs.3.rs-350465/v1

License: (1) (i) This work is licensed under a Creative Commons Attribution 4.0 International License. Read Full License 


\section{Abstract}

The situation of high energy consumption in construction industry is becoming increasingly severe, which hinders the sustainable development of world economy, society and environment. Building energy conservation reconstruction is urgent. The long-term and effective promote of buildings energy conservation reconstruction depends on the market development. However, its external characteristics and public goods attributes determine it is necessity of implementing incentives. The incentives of the buildings energy conservation reconstruction market development not limited in policy incentives, involving multiple influencing factors, which are interrelated and complex systems engineering. Therefore, it is necessary to integrate many factors into a coordinated dynamic system. This paper uses literature analysis method and expert interview method to identify the factors that affect incentives of buildings energy conservation reconstruction market development. In this study, the incentive structure frameworks of incentive elements, incentive operation, incentive efficiency and incentive environment were constructed by using the whole and part research idea. Based on principle of dynamic feedback analysis, Vensiem PLE was used to respectively analysis the four subsystem causality diagrams, the dynamic feedback relationship among the influencing factors in each incentive subsystem were clarified. The results demonstrate that incentive goal consistency, inspire all links, incentive system integrity and market maturity are the key factors affecting the incentive effect of the whole system. Finally, some optimization suggestions on incentive mechanism are put forward to promote the buildings energy conservation reconstruction market development.

\section{Introduction}

Today, the world is facing an increasing energy and environment crisis. Many countries have recognized the importance of improving energy efficiency and reducing energy use for sustainable development. The huge size of buildings in the world has higher energy efficiency potential than other industries (Ballarini et al.2014). About $75 \%$ of the European Union' (EU) buildings are constructed without energy efficiency specifications (Vorsatz et al.2007). It is estimated that about $75-90 \%$ of the permanent buildings in the EU will continue to be used in 2050 (Dall et al.2012). A large number of nonenergy saving buildings not only increase the energy burden, but also exacerbate the restrictive role of resource constraints on sustainable development of cities. By the end of 2018, China adds 2 billion square meters of new buildings every year (Ballarini et al.2014), and this proportion will continue to grow with the promotion of urbanization. In view of the dependence on energy and the compromise on climate change, buildings energy conservation also constitutes a strategic objective of the EU. The buildings energy conservation reconstruction market has huge development space and promotion potential. However, the public goods characteristics and positive externality of buildings energy saving reconstruction determine that market development is inevitably inseparable from incentive mechanism. The purpose of implementing incentives is to improve the initiative of market entities, enhance the comprehensive benefits of energy conservation reconstruction, and promote market development. 
Since the first energy crisis broke out in 1973, western countries have made many explorations in incentives for buildings energy conservation reconstruction. It mainly focuses on coordination and cooperation of market entities, multiple combinations of incentive measures, and optimization and upgrading of incentive systems. In terms of market subjects, Japan set up a four-level "pyramid" energy saving management organization, with the leadership of the Prime Minister as the core and multidepartment coordination (Fawkes et al .1986). The United States (US) government has constructed a multi-level building energy conservation management system (Bonner et al.2018). In terms of incentive measures, the Japanese government combined engineering demonstration and technological innovation to fully mobilize owners and energy service companies (ESCO). The Britain adopted a combination of financial subsidies, tax incentives and an energy consumption tax (Fawkes et al.1986). Compared with mandatory regulation and a single incentive, a flexible and diverse combination of economic incentives is more conducive to enhancing incentive effect. In terms of the incentive system, the developed countries have optimized implementation path of the energy conservation incentive system through government financial support, market credit information management, and industrialization. The US established the Energy Conservation Public Welfare Fund to provide financial support for energy conservation technological innovation. The German government set up the Renaissance Credit Bank to broaden financing channels. The Japanese government formulated industrialization development policies in accordance with local conditions in different regions. The EU countries established ESCO qualification credit system and ESCO credit file to foster a good industrial development environment (Carvallo et al,2019).

This paper aims to study many factors that influence incentive of the building energy conservation reconstruction market development from an overall perspective. Under the premise of constructing system analysis frameworks, system dynamics models are built to clarity the dynamic feedback relationship among incentive factors in the system, and the action process of various incentive factors on market development is revealed. It avoids the drawback of neglecting the relationship among factors in previous studies, and provides theoretical support for government to formulate more effective incentive policies, so as to improve incentive benefits, achieve good incentive affect, and promote efficient and orderly operation of buildings energy conservation reconstruction market.

The remainder of this paper is structured as follows: Sect. 2 introduces research materials methods of dynamic feedback analysis. Section 3 constructs the model for research demonstration and result analysis. Section 4 further discusses this research. Section 5 summarizes the full text.

\section{Materials And Methods}

Forrester (Forrester,2010) of MIT proposed system dynamics in 1956. He pointed that system's goal is not to find the optimal solution, but to seek measures and ways to improve the system output on basis of the system. The process of information transmission and causal feedback among various factors of the system can be obtained by dynamic feedback analysis. So far, many scholars have used it in research. For example, Homer (2006) used it to explore the dynamic complexity of public health problems. 
Ghaffarzadegan (2011) tried to use it to help formulate public policy. Nazareth (2011) applied it to information security management. In general, the dynamic feedback analysis process has the following six steps.

\subsection{Proposing Dynamic Hypothesis}

According to causes of research objectives, in order to facilitate analysis, the following potential hypotheses are stored in the feedback view of system dynamics.

1. The system is an evolving, continuous, and gradual process.

2. The system does not consider sudden changes in system status due to abnormal factors such as war, disease, etc.

3. The system operation effect is determined by the interaction of influencing factors and system environmental factors.

\subsection{Determining System Boundary}

In order to start with the problem and really focus on the core issue, we can consider ignoring the less important factors and draw the system boundary according to research purpose and actual situation. Dynamic feedback analysis mainly studies variables inside the system (Thoms et al.2011). This is because endogenous variables are determined by the system internal feedback structure, while exogenous variables change with time, and cannot fundamentally affect the system operation (Wu et al.2012). Therefore, dynamic feedback analysis needs to define system boundary according to research objectives and practical issues.

\subsection{Drawing System Structure Diagrams}

The system structure diagram is a summary and should not contain too much detail (Oliva et al.2010). The structure diagrams focus on modeling, which assumes that decision makers use information about the traffic in the control system, which shows the causal structure and time delay involved in a particular decision, rather than the feedback structure of the entire system. The research idea of this step is to divide the whole system into several subsystems, and analyze each subsystem structure in depth to study the interaction between each subsystem.

\subsection{Building System Feedback Model}

Similar to step 2.3, the research idea of the whole and then the part is adopted. Firstly, Vensim PLE is used to draw total system feedback model based on sorting out the system influencing factors, Secondly, the total system is divided into several subsystems to deeply analyze the correlation of internal variables.

\subsection{Analyzing System Causality}

The causal arrow " $\rightarrow$ " is a directed line segment connecting the causal variables. The arrow tail begins with the cause and ends with the result, and the two variables connected by the causal arrow become a 
causal chain. Causal chain only reflects the logical relationship or change direction between variables (Nesheim et al.2014). Causality can be divided into positive and negative poles, "+" means that the variables of link change in same direction, and causality is strengthened. On the contrary, "-" means that the variables of link change in opposite direction, and causality is weakened. When determining the positive or negative of a causal chain or a causal loop, it is assumed that all variables outside the chain or ring are constant. If there are odd-numbered causal chains with negative polarity, it is a causal chain with negative polarity. If there are even-numbered causal chains with negative polarity, it is a causal chain with positive polarity (Barunik.2018) (Fig. 1).

Multiple causal chain interacts to forms a causal loop, called a feedback loop. It is a closed, first-order causal chain, and its polarity criterion is the same as a causal chain. The positive feedback loop indicates that the change of any variable in the loop will cause the change of other variables in the loop along the direction indicated by the arrow. At the same time, the change of other variables will promote the change of the variable (Agnew et al.2018). Conversely, if the change of any variable in the loop will restrain the change of other variables, the loop will become a negative feedback loop, also known as the balance loop (Li et al.2015) (Fig. 2).

However, practical problems are often very complex and can't be clearly described with a few causal chains or loop. A complex set of causal chains or loops is called a causal graph (Homer et al.2006). The drawing of causality diagram should be based on finding out as many variables as possible, and then start with any variable in the system, find all variables that have direct causal relationship with this variable, and determine the relationship among them and all causal chains should have clear polarity (Beck et al.2010). It should be noted here that in determining relationship between two variables, it is necessary to assume that other factors are fixed and pay attention to some special cases, such as mutual causation, one cause many effects, and multiple causes one effect. Repeat this process until all causal relationships are completed. Causality diagrams can describe causality between variables, and expresses correlation and feedback process among variables in the system (Thiem et al.2014).

\subsection{Analyzing System Characteristics and Key Influencing Factors}

Edmondson (2018) has demonstrated that system dynamics is a scientific tool to analyze dynamic feedback relationships among many influencing factors in a system. Based on the results of dynamic feedback analysis, the characteristics and the key influencing factors of complex system are obtained.

\section{Results}

\subsection{The Incentive Influencing Factor of Buildings Energy Conservation Reconstruction Market Development}

So far, there have been many studies on buildings energy conservation reconstruction at home and abroad. Although the national conditions are not the same, the central position of government incentive 
in buildings energy conservation reconstruction markets development has become a common consensus among researchers in this field. A detailed summary of previous research, we found that the research on incentive factors of the buildings energy conservation reconstruction mainly concentrated in market intrinsic characteristics, market operation mode, market development constraints, government incentive policies, and behavior choice of incentive objects. Sebi (2019) pointed out that government gains social and environmental benefits from energy conservation reconstruction and should play a leading role in market development. Soroye (2010) believed that externality result in failure of energy conservation reconstruction, and economic incentive is the most direct and effective means for the government to intervene in market economy to optimize resource allocation. Hamilton (2014) through that owners' enthusiasm for energy conservation reconstruction is affected by externalities, and suggested that the degree of implementation of incentive policies is directly proportional to the owners' enthusiasm. Wong (2017) pointed out that energy efficiency labeling system is an effective information disclosure measure that can effectively weaken information asymmetry and enhance market transparency. Fuerst (2015) pointed out that EPC stipulates energy saving behavior by signing a contract period. Droutsa (2016) found that the introduction of EPC mode into energy conservation reconstruction market can promote ESCO to share energy conservation benefits with owners, and coordinate the interest conflict of the industry chain subject. Krarti (2015) believed that institutional factors such as energy prices and market structure are obstacles facing the energy efficiency service market in all countries. Bjorneboe (2018) found that the main obstacles in energy conservation service market are the owners' lack of energy saving awareness and the imperfect of market supervision system. Arumagi (2014) demonstrated that the energy conservation technology should be adapted to local conditions. Gram (2012) believed that the linkage between energy saving market and strategic emerging industries such as the Internet, new energy is insufficient, and no effective external interaction and support development model has been formed. Chowdhury (2014) found that green buildings constrained by the government's economic incentive policy, the supervision of the construction industry and the technical ability. Carlssonkanyama (2010) believed that information transfer, economic incentives, management tools and technical support are the key to promote the market development. Friege (2014) believed that countries should formulate individualized economic incentives including information and taxation to adapt to their own markets according to their own development characteristics. Painuly (2003) pointed out that financing barrier is one of the difficulties in ESCO development. Government should encourage financial institutions to establish specialized financing platforms and provide specialized financing products. Blengini (2010) emphasized the multiple combinations of incentives such as economic incentive, cultural incentive, and institutional incentive. Risholt (2013) pointed out that the key to building energy conservation is to improve the owner's awareness of energy conservation, and pointed out that knowledge, motivation and control are the main factors that can encourage owners to adopt energy conservation behavior. Capelo (2013) analyzed the impact of energy efficiency policies on ESCO in EU countries, through a Portuguese case study. Toleikyte (2018) applied different energy conservation potential cost curves to select the lowest cost energy efficiency solutions based on the perspective of investors and overall economy. Liu (2018) determined that the reasonable setting of incentive process is the key factor of incentive for market development through SWOT analysis. Paiho (2015) proposed a programmatic economic model to assess 
the effectiveness of government economic incentives. Pombo (2016) adopted a multi-criteria evaluation method and found that government incentives should focus on the coordination between energy conservation and environmental, economic and social benefits. Vine's survey revealed the positive correlation between the information interaction between ESCO and government organizations (2015).

Using literature analysis, expert interviews, case studies and other technologies, combined with own experience and observation, this paper obtains the following 33 incentives factors of the buildings energy conservation reconstruction market development: ESCO service level (Painuly et al.2003), ESCO economic benefits(Wong et al.2017), market development maturity(Droutsa et al.2016), the cooperate willingness of market subject(Arumagi et al.2014), a sound market mechanism(Friege et al.2014), the energy conservation willingness of market subject (Arumagi et al.2014), incentives efficiency(Droutsa et al.2016), reconstruction demand(Bjorneboe et al.2018), incentive goal divergence, organization internal management efficiency (Paiho et al.2015),consistency of incentive goal(Pombo et al.2016), interorganizational information interaction(Blengini et al.2010), improvement of incentive system(Carlssonkanyama et al.2010), incentive economic benefit(Bjorneboe et al.2018), appropriateness of incentive intensity(Carlssonkanyama et al.2010), effectiveness of incentives(Liu et al.2018), inspire all links (Krarti et al.2015), implementing effect of incentive means(Chowdhur et al.2014), incentive cost (Krarti et al.2015), incentive effect feedback(Wong et al.2017), the implementation effect of incentive means(Painuly et al.2003), the choice of incentive policy combination[(Krarti et al.2015), the matching degree of policy and market subject demand(Friege et al.2014), the identification of market subject demand(Arumagi et al.2014), incentive policy updates(Friege et al.2014), the difference of market subject demand(Risholt.2013), incentive utility(Liu et al.2018), market development prospects, energy conservation product innovation(Tuominen et al.2012), the change of organizational environment(Painuly et al.2003), market information interaction, coordination of industry chain, system innovation capability(Painuly et al.2003).

\subsection{The Incentive System Structure of Buildings Energy Conservation Reconstruction Market Development}

Based on systematic view, the incentive system of buildings energy conservation reconstruction market development has dissipative structure. Each subsystem coordinates mutually, forms a stable and orderly structure spontaneously, and has a strong logical relationship. Considering the law of market development, the complex incentive system of buildings energy conservation reconstruction market is divided into incentive element subsystem, incentive operation subsystem, incentive efficiency subsystem, and incentive environment subsystem. Each subsystem has different characteristics to maintain the balance and stability of entire system. The four subsystems of incentive elements, incentive operation, incentive environment and incentive performance cross-impact and mutually restrict each other to form a feedback system. Figure 3 shows the structural framework and relationships of the four subsystems in incentive system. 


\subsubsection{The Structure of Incentive Elements Subsystem}

The incentive elements subsystem is the core of incentive system of the buildings energy conservation reconstruction market development. It contains incentive subjects, incentive objects, and incentive tools. It is a self-organized complex system. The structure of incentive elements subsystem is shown in Figure 4.

\subsubsection{The Structure of Incentive Operation Subsystem}

The incentive operating subsystem is the foundation of incentive system and the necessary condition of incentive elements subsystem. By controlling and coordinating the various operational links of the incentive system, the government maximizes the role of the incentive elements subsystem and ultimately realizes sustainable development of the building energy conservation reconstruction market. The structure of the incentive operating subsystem is shown in Figure 5.

\subsubsection{The Structure of Incentive Efficiency Subsystem}

The incentive efficiency subsystem reflects the operation efficiency of incentive system for the buildings energy conservation reconstruction market development, and is an important subsystem to measure the incentives effectiveness. The structure of incentive efficiency subsystem is shown in Figure 6.

\subsubsection{The Structure of Incentive Environment Subsystem}

The incentive environment subsystem is closely related to the other three subsystems, which not only provides linkage support for the implementation of incentive paths, but also provides ideas for collaborative development and innovative collaboration with other related industries. The structure of the incentive environment subsystem is shown in Figure 7.

\subsection{Building Total System Causal Diagram}

Based on obtaining the influencing factors, namely the system variables, the causal relationship between variables is extracted from interviews with authoritative experts, and the causal chain is supported by a paragraph in interviews. In addition, according to their own experience and observations, the historical data and other information sources, add additional causal chains not mentioned in interviews or other sources, in order to build a better system dynamics model. Start with any variable and explore all variables within the system that are causally related to the variable until all variables' causal effect is completed, as shown in Figure 8.

We can clearly see that the total system involves many variables. It's hard to directly analyze dynamic feedback relationship of all variables. Therefore, it is necessary to carry out dynamic feedback analysis for four subsystems separately (Serrano et al.2019). According to the structure analysis and interrelationship of incentive system for the buildings energy conservation reconstruction, we can get that the four subsystems of incentive elements, incentive operation, incentive environment and incentive performance promote and restrict each other to form a multi-feedback incentive system of market 
development(Almeida et al.2018). It is helpful for the research and demonstration of the total system to analyze the dynamic feedback relationship of the four subsystems' influencing factors separately.

\subsection{Results Analysis of System Dynamic Feedback}

\subsubsection{The Incentive Elements Subsystem}

The feedback relationship of incentive elements subsystem reflects interaction of incentive elements in the building energy conservation reconstruction market development. The synergistic interaction among incentive elements is the key to achieve incentive effect. The relationships among influencing factors of the incentive elements subsystem are shown in Figure 9.

As can be seen from Figure 9, the two main feedback loops of the incentive elements subsystem are as follows:

1) Incentive goal consistency $\rightarrow(+)$ Organization internal management efficiency $\rightarrow(-)$ incentive subject goal divergence $\rightarrow(-)$ Incentive implementation efficiency $\rightarrow(+)$ Incentive effectiveness $\rightarrow(+)$ Appropriateness of incentive intensity $\rightarrow(-)$ Incentive cost $\rightarrow(-)$ Incentive economic benefits $\rightarrow(+)$ Incentive system perfection $\rightarrow(+)$ Incentive goal consistency.

This loop has positive polarity. This shows that goal consistency can affect project incentive effect. Therefore, in the design stage of incentive path, government should focus on formulating unified incentive goals, improving the management efficiency within organization, reducing goal divergence of incentive subjects, improving efficiency of incentive implementation, and reducing incentive costs, so as to further improve the incentive system and enhance the consistency of incentive goal.

2) Incentive goal consistency $\rightarrow(+)$ Inter-organizational information interaction $\rightarrow(+)$ Incentive implementation efficiency $\rightarrow(+)$ Incentive effectiveness $\rightarrow(+)$ Market subject energy-saving awareness $\rightarrow(+)$ Renovation demand $\rightarrow(+)$ ESCO economic benefits $\rightarrow(+)$ ESCO service level $\rightarrow(+)$ Sound market mechanism $\rightarrow(+)$ The cooperate willingness of market subject $\rightarrow(+)$ Market development maturity $\rightarrow$ $(+)$ Incentive goal consistency.

This loop has negative polarity, from which it can be concluded that inter-organizational information interaction is essential to improve efficiency of incentive implementation. It can help to enhance the cooperate willingness of market subject, thereby improving the incentive system, promoting market development.

From the above two feedback loops, we found that organization internal management efficiency and inter-organizational information interaction are the key factors to improve the incentive goal consistency. Through continuous interacting with other factors, the implementation effect of incentives will be affected, the market mechanism will be improved, and subjects' enthusiasm and willingness to cooperate will be enhanced. 


\subsubsection{The Incentive Operation Subsystem}

The incentive operation subsystem mainly improves effectiveness of incentive implementation by strengthening the linkage of incentive links. The causal feedback relationships among the influencing factors in the incentive operation subsystem are shown in Figure 10.

As can be seen from the analysis in Figure 10, the three main feedback loops of the incentive operation subsystem are as follows:

1) Inspire all links $\rightarrow(+)$ Inter-organizations information interaction $\rightarrow(+)$ Incentive implementation efficiency $\rightarrow(-)$ Incentive costs $\rightarrow(-)$ Incentive economic benefits $\rightarrow(+)$ Improve incentive system $\rightarrow(+)$ Incentive policy update $\rightarrow(+)$ Inspire all links.

This loop has positive polarity, which promotes information interaction among organizations by enhancing the inspire of each link, improving the efficiency of incentive implementation, reducing incentive cost, improving incentive income, thereby accelerating policy update, and enhancing their enthusiasm of energy conservation reconstruction.

2) Inspire all links $\rightarrow(+)$ Market subject demand identification $\rightarrow(+)$ Policy and market subject demand matching $\rightarrow(+)$ Selection of incentive policy mix $\rightarrow(+)$ Implementing effect of incentive means $\rightarrow(+)$ Willingness of market subject to cooperate $\rightarrow(+)$ Market development maturity $\rightarrow(+)$ Market subject demand difference $\rightarrow(+)$ Incentive policy update $\rightarrow(+)$ Inspire all links.

This loop has positive polarity, which proves that linkages in the implementation are important. By improving the accuracy of market demand identification, strengthening the matching of policy and market demand, improving the effect of incentive implementation, and promoting market development. With the market's gradual maturity, the demand differences among market subjects become more and more apparent, and policies are constantly updated. In order to meet the changing needs of market subject, it is necessary to promote the linkage of all links of incentive.

3) Inspire all links $\rightarrow(+)$ Market subject demand identification $\rightarrow(+)$ Policy and market demand matching $\rightarrow(+)$ Selection of incentive policy mix $\rightarrow(+)$ Implementation effect of incentive means $\rightarrow$ $(+)$ Feedback of incentive effect $\rightarrow(+)$ Improve incentive system $\rightarrow(+)$ Incentive policy update $\rightarrow(+)$ Inspire all links.

This loop is a positive feedback loop. Its significance is to improve the incentive system by enhancing incentive effect, improving incentives effectiveness, optimizing incentive system, and improving incentives linkage.

From the above three positive feedback loops, the key factors to improve the effect of incentive implementation are the linkage of each links, the matching of policy and market demand, and the feedback of incentive effect. 


\subsubsection{The Incentive Efficiency Subsystem}

Government pays attention to the balance of incentive costs and benefits while promoting social progress and social welfare. Therefore, government incentive also has bounded rationality. The causality of influencing factors of the incentive efficiency subsystems is shown in Figure 11.

As can be seen from Figure 11, the three main feedback loops of the incentive efficiency subsystem are as follows:

1) Improve incentive system $\rightarrow(+)$ Incentive implementation efficiency $\rightarrow(+)$ Incentive means Implementation effect $\rightarrow(+)$ Reconstruction demand $\rightarrow(+)$ ESCO economic benefits $\rightarrow(+)$ Energy saving product innovation $\rightarrow(+)$ Market development prospects $\rightarrow(+)$ Incentive economic benefit $\rightarrow(+)$ Improve incentive system.

2) Improve incentive system $\rightarrow(+)$ Incentive implementation efficiency $\rightarrow(+)$ Incentive means implementation effect $\rightarrow(+)$ Renovation demand $\rightarrow(+)$ ESCO economic benefits $\rightarrow(+)$ ESCO service level $\rightarrow(+)$ The cooperate willingness of market subject $\rightarrow(+)$ Incentive utility $\rightarrow(+)$ Incentive economic benefits $\rightarrow(+)$ Improve incentive system.

3) Improve incentive system $\rightarrow(+)$ Policy and market demand matching $\rightarrow(+)$ Appropriateness of incentive intensity $\rightarrow(+)$ Market main subject's energy-saving consciousness $\rightarrow(+)$ The cooperate willingness of market subject $\rightarrow(+)$ Incentive utility $\rightarrow(+)$ Incentive economic benefits $\rightarrow(+)$ Improve incentive system.

The above three loops are positive feedback loops, which mainly reflects that perfect incentive system can not only promote energy conservation products and technological innovation, promote market development, but also improve the ESCO economic benefits effectively, and achieve incentive effects better.

\subsubsection{The Incentive Environment Subsystem}

The incentive environment subsystems of the buildings energy conservation reconstruction market development mainly focus on market characteristics and dynamic changes in the environment at different stages of market development impact on each incentive subsystem. The causal feedback relationships between the various factors in the incentive environment subsystem are shown in Figure 12.

In Figure 12, the four main feedback loops of the incentive environment subsystem are as follows:

1)Market development maturity $\rightarrow(+)$ Incentive system perfection $\rightarrow(+)$ Economic externalities $\rightarrow(+)$ Market subject energy saving awareness $\rightarrow(+)$ The cooperate willingness of market subject $\rightarrow(+)$ Market development prospects $\rightarrow(+)$ Market development maturity.

2) Market development maturity $\rightarrow(+)$ Market information interaction $\rightarrow(-)$ Information asymmetry $\rightarrow(-)$ The cooperate willingness of market subject $\rightarrow(+)$ Market development prospects $\rightarrow(+)$ Market development maturity. 
3) Market development maturity $\rightarrow(+)$ Market information interaction $\rightarrow(+)$ Coordination of industry chain $\rightarrow(+)$ System innovation capability $\rightarrow(+)$ Energy saving product innovation $\rightarrow(+)$ The cooperate willingness of market subject $\rightarrow(+)$ Market development prospects $\rightarrow(+)$ Market development maturity.

4) Improve incentive system $\rightarrow(-)$ Organizational environment change $\rightarrow(-)$ Incentive goal consistency $\rightarrow(+)$ Internal management efficiency of organization $\rightarrow(-)$ Incentive subject goal divergence $\rightarrow(-)$ Incentive effectiveness $\rightarrow(+)$ Incentive economic benefit $\rightarrow(+)$ Improve incentive system.

The above four loops are all positive feedback loops, which mainly reflect that with market development, the incentive system is more perfect, and can effectively reduce the impact of environmental factors such as economic externalities, information asymmetry, change of organizational environment and so on. At the same time, environmental factors such as market information interaction and the coordination degree of industry subjects can also promote improvement of incentive system and market maturity.

\subsection{The Characteristics of Incentives System}

Through the above analysis, the characteristics of incentive system of the buildings energy conservation reconstruction market development are as follows:

1) Effective coordination among subsystems is the key to orderly operation of incentive system. The four subsystems of incentive elements, incentive operation, incentive efficiency, and incentive environment promote and influence each other. The promotion of incentive efficiency subsystem is based on the coordination of other three subsystems. The interaction among subsystems promotes the overall coordination, feedback control, and gradual improve of the incentive system.

2) Any change in one variable in the system will cause the change of other variables. Systematic theory emphasizes the relationship among multiple variables, and incentive factors that affect the buildings energy conservation reconstruction market development are not isolated. For example, strengthening the linkage of incentive links can affect and promote the information interaction between organizations, thereby affecting the efficiency of incentive implementation, improving the economic efficiency of incentive, and improving the incentive system, thus affecting effect of the buildings energy saving reconstruction market operation. Therefore, we should consider the dynamic changes of the whole system when design incentive path of energy conservation reconstruction market. In this process, the incentive mechanism should be continuously optimized to accelerate market development.

3) The incentive system circulation channel is information interaction, which realizes the identification of market demand and the feedback of incentive effect. The identification of market subjects' demand, the feedback of incentive effects, market information, and information interaction between organizations are the driving forces for circular feedback of entire incentive system. Information interaction can also effectively attenuate the information asymmetry of the market, and eliminate the cooperation doubts of market participants, and promote mutual trust and win-win cooperation between market subjects. 
4) The operation of incentive system needs pay attention to the dynamics of market development stage. Buildings energy conservation reconstruction market is not fixed, and the factors changes of incentive system generally conform to the track of market evolution. We should pay attention to subject demand and behavior evolution law at different stages, consider the influence of incentive policy update, attach importance to the matching degree between policy and market demand, pay attention to the market environment and industry development trend in different stages, and adjust and optimize the incentive mechanism in time.

\section{Discussion}

Building energy conservation reconstruction is integrated into urban repair strategy of ecological concept, which can effectively replace large-scale demolition and construction in the process of urban renewal. It is the key link to save energy and reduce carbon emissions. The following discussion is based on the results obtained in Sect. 3.

1. Figure 11 indicates that incentive goal consistency is a key factor of the incentive elements subsystem. The consistency of incentive goal determines incentive implementation effect, improves the management efficiency and information interaction between organizations to promote efficiency of the incentive implementation. At present, the subject's goals of the building energy conservation reconstruction are seriously divided in China, governments at all levels of incentive method are different, the recognition of market subject needs are not accurate, policy and market subject needs matching degree is not high. There is a lack of a set of incentive paths suitable of the current energy conservation reconstruction market.

2. As expected, the key to improve efficiency of incentive implementation is the linkage of incentive links. Figure 10 show that the linkage of each link determines the implementation efficiency of incentive and affects the implementation effect of incentive and the enthusiasm of market subjects. Improving the accuracy of subject demand identification can enhance the matching degree between policies and market demand, and improving the effect of incentive implementation. The market matures in the process of continuous development, economic incentive policies are updated, and finally achieve feedback optimization of all links of incentive operation to promote the healthy and orderly development of energy conservation reconstruction market.

3. "Incentive system integrity" has attracted wide attention in social circles. Figure 11 can prove the importance of "incentive performance", which not only reflects the operational efficiency, but also measures effectiveness of government incentives. With the continuous improvement of the incentive system, the incentives effectiveness is improved, the incentive costs are gradually reduced, and the incentive utility is gradually improved. Incentive performance is gradually improved based on the input-output perspective. The improvement of incentive efficiency in turn continues to promote improvement of the market development system.

4. An interesting finding is that market maturity can no longer be ignored, Fig. 12 displays that maturity of the building energy saving reconstruction market has an impact on government, owners, ESCO and other subject's behaviors, economic growth, and institutional guarantee mechanisms, which 
indirectly affects incentive implementation effect and integrity of the incentive system. The incentive system interacts with market maturity and promotes each other to form a self-organizing system with cyclic feedback.

\section{Conclusions}

Building energy conservation reconstruction has important strategic significance for alleviating the current situation of energy shortage in the world, building low-carbon cities, and improving people's living environment. Its public goods attribute determines that incentives are essential for guiding market development. This paper analyses the dynamic feedback of influencing factors and explores incentives mechanism from a systematic perspective to achieve better incentive effect in the building energy conservation reconstruction market. Based on the results of system analysis, focusing on industrial practices, the following recommendations are made to achieve better incentive effects of the buildings energy conservation reconstruction market.

1. Set up energy conservation reconstruction management departments and coordinate rights and responsibility between governments at all levels. First of all, starting with the coordination of government energy conservation service manage departments, standardizing and clarifying the rights and responsibilities of various departments. Secondly, improve the assessment system of incentive policies implementation. The effect of policy incentives should not only stay in the area of energy saving industry, but also strengthen the interaction and sharing of information with the government and departments. Thirdly, building a feedback platform make the incentive system more dynamic. Finally, supporting the development of third-party energy conservation service organizations such as industry associations and research institutions, use social subjects' power to regulate the market order, and build a bridge of information transmission and feedback between market subject and government departments.

2. Creating a healthy market development policy environment and guiding market subjects to achieving win-win cooperation. On the one hand, ESCO, as the main supplier of energy conservation service products, encourages them to establish management mechanisms of value co-creating. This measure makes owners more confident in the quality of energy conservation services provided by ESCO in the process of participating in energy conservation services, and helps both sides to form a cooperative situation of risk-sharing and benefit-sharing. On the other hand, strengthen the cultivation of market-assisted entities, reward individuals or enterprises that innovate in energy conservation service models and technological innovations in energy conservation products, build innovative cooperation platforms, give full play to the joint action of industry, support institutions such as universities, research institutes, financial institutions, and third-party institutions, and form a market development environment of value creation and win-win cooperation.

3. On the premise of matching policy and market demand, the combination of incentive policy measures is applied. First, identify the market subjects' demand characteristics at different stages of market development accurately, give full play to the market demand survey results of industry associations and third-party testing institutions, and select incentives that match the market 
development needs flexibly. Second, analyzes the limitations of each incentive policy and pays attention to the transition among various policies. Establish principles and selection mechanism for combination of incentive policies, and evaluate the effect of policy portfolio implementation to further optimize combination and minimize incentive costs.

\section{Declarations}

Ethics Approval and Consent to Participate: Not applicable.

Consent for Publication: Not applicable.

Availability of Data and Materials: All data generated or analysed during this study are included in this published article [and its supplementary information files].

Competing Interests: The authors declare that they have no competing interests.

Funding: This research was funded by the National Natural Science Foundation of China (71872122), Philosophy and Social Science Research Project of Ministry of Education(20JHQ095). Higher Education Innovation Team of Tianjin (TD13-5006).

Author Contributions: Investigation, X.W. and W.Q.; Methodology, W.Q. and X.W.; Project administration, H.G.; Software, W.Q.; Supervision, H.G.; Validation, W.Q. and X.W.; Writing - original draft, W.Q. and X.W.; Writing - review \& editing, W.Q. All authors have read and agreed to the published version of the manuscript.

\section{References}

1. Agnew.S., Smith.C, and Dargusch.P. Causal loop modelling of residential solar and battery adoption dynamics: A case study of Queensland, Australia. J. Clean. Prod. 2018, 172, 2363-2373

2. Almeida M, Ferreira M (2018) Ten questions concerning cost-effective energy and carbon emissions optimization in building renovation. Build 143:15-23 Environ,

3. Arumagi.E. and Kalamees T (2014) Analysis of energy economic renovation for historic wooden apartment buildings in cold climates. Appl 115:540-548 Energy,

4. Corgnati Ballarinil (2014) S.P., and Corrado.V. Use of reference buildings to assess the energy saving potentials of the residential building stock: The experience of TABULA project. Energy Policy 68:273284

5. Barunik J (2018) and Krehlik.T. Measuring the Frequency Dynamics of Financial Connectedness and Systemic Risk. J financ econ 16:271-296

6. Beck SR, Riggs KJ (2010) and Gorniak.S. L. The effect of causal chain length on counterfactual conditional reasoning. $\mathrm{Br}$ 3:505-521 J D Psychol, 
7. Bjorneboe MG, Svendsen. S. and Heller A (2018) Initiatives for the energy renovation of single-family houses in Denmark evaluated on the basis of barriers and motivators. Energ Buildings 167:347-358

8. Blengini GA, Dicarlo T (2010) Energy-saving policies and low-energy residential buildings: an LCA case study to support decision makers in Piedmont (Italy). Int J Life Cycle ass 15:652-665

9. Bonner.I McNunnG (2018) and Muth.D. Development of integrated bioenergy production systems using precision conservation and multicriteria decision analysis techniques. J 71:182-193 Soil Water Conserv,

10. Capelo. C., Dias. J. F. and Pereira.R. A system dynamics approach to analyze the impact of energy efficiency policy on ESCO ventures in European Union countries: a case study of Portugal. Energy Effic.2018, 11, 893-925.

11. Carlssonkanyama A (2010) Lindén. A. and Eriksson.B. Residential energy behaviour: does generation matter? Int 29:239-253 J C Stud,

12. Stuart CarvalloJP,MurphySP (2019) E, et al. Evaluating project level investment trends for the U.S. ESCO industry: 1990-2017. Energy Policy 130:139-161

13. Chowdhury S (2014) Sumita. U.and Islam. A. Importance of policy for energy system transformation: Diffusion of PV technology in Japan and Germany. Energy Policy 68:285-293

14. Galante DallG.A, and Pasetti.G. A methodology for evaluating the potential energy savings of retrofitting residential building stocks. Sustain. Cities Soc. 2012, 4, 12-21

15. Droutsa. K. G., Kontoyiannidis. S. and Dascalaki.E. G. Mapping the energy performance of hellenic residential buildings from EPC (energy performance certificate) data. Energy 2016, 98, 284-295.

16. Edmondson. D. L., Kern. F., and Rogge. K. S. The co-evolution of policy mixes and socio-technical systems: Towards a conceptual framework of policy mix feedback in sustainability transitions. Res. Policy. 2018, 40.

17. Fawkes SD (1986) A comparison of British and Japanese industrial energy management. $R \mathrm{i}^{1} 1 / 4 \quad D$ Manage 4, no.(16):309-316

18. Forrester JW, System, Dynamics (2010) Systems Thinking, and Soft OR. System Dynamics Review 10:245-256

19. Friege. J. and Chappin E (2014) Modelling decisions on energy-efficient renovations: A review. Renew 39:196-208 S Energy Rev,

20. Fuerst. F., Mcallister. P. and Nanda. A. Does energy efficiency matter to home-buyers? An investigation of EPC ratings and transaction prices in England. Energy Econ 2015, 48, 145-156.

21. Ghaffarzadegan.N., Lyneis.J, and Richardson. G. P. How small system dynamics models can help the public policy process. Syst. Dyn. Rev. 2011, 27, 22-44

22. Hamilton.I.G.,Shipworth.D. and Summerfield A (2014) J. Uptake of energy efficiency interventions in English dwellings. Build 42:255-275 res. inf,

23. Hannon MJ (2015) and Bolton. R. UK Local Authority engagement with the Energy Service Company (ESCo) model: Key characteristics, benefits, limitations and considerations. Energy Policy 78:198- 
212

24. Homer. J. B., and Hirsch. G. B. System Dynamics Modeling for Public Health: Background and Opportunities. Am. J. Public Health 2006, 96, 452-458

25. Homer.J.B., and Hirsch. G. B. System Dynamics Modeling for Public Health: Background and Opportunities. Am J Public Health 2006, 3, 452-458

26. Krarti M (2015) Evaluation of large scale building energy efficiency retrofit program in Kuwait. Renew. Sust 50:1069-1080 E Rev,

27. Li YM, Tong SC,and Li.T.S. Adaptive Fuzzy Output Feedback Dynamic Surface Control of Interconnected Nonlinear Pure-Feedback Systems. IEEE Trans Cybern. 2015, 45, 138-149

28. Liu G (2018) Zheng. S. and Xu.P. An ANP-SWOT approach for ESCOs industry strategies in Chinese building sectors. Renew 93:90-99 S E Rev,

29. Mirchi A, Madani K, Watkins D, et al. Synthesis of System Dynamics Tools for Holistic Conceptualization of Water Resources Problems. Water Resour. Manag. 2012, 26

30. Nazareth D, L, and Choi (2015) J. A system dynamics model for information security management. Inf 1:123-134 Manage,

31. Nesheim I, Reidsma. P. and Bezlepkina I (2014) Causal chains, policy trade offs and sustainability: Analysing land (mis) use in seven countries in the South. Land Use Pol 37:60-70

32. Oliva R (2010) Model structure analysis through graph theory: partition heuristics and feedback structure decomposition. Syst 4:313-336 D Rev,

33. Paiho S, Abdurafikov. R. and Hoang H (2015) Cost analyses of energy-efficient renovations of a Moscow residential district. Sustain cities soc 14:5-15

34. Painuly. J. P., Park. H. and Lee.M. K. Promoting energy efficiency financing and ESCO in developing countries: Mechanisms and barriers. J. Clean Prod. 2003, 6, 651-657

35. Pombo RO (2016) Rivela. C. B. and Neila. G. F. J. The challenge of sustainable building renovation: assessment of current criteria and future outlook. J 123:88-100 Clean. Prod,

36. Risholt B, Berker T (2013) Success for energy efficient renovation of dwellings-Learning from private homeowners. Energy Policy 61:1022-1030

37. Sebi C (2019) Nadel. S. and Schlomann.B. Policy strategies for achieving large long-term savings from retrofitting existing buildings. Energy Effic 12:89-105

38. Serrano. J., Antonio. L. and Jesus M (2019) Decision-support method for profitable residential energy retrofitting. J 222:622-632 Clean Prod

39. Soroye. K. L., and Nilsson. L. J. Building a business to close the efficiency gap: the Swedish ESCO experience. Energy Effic 2010, 3, 237-256.

40. Thiem.A. Using Qualitative Comparative Analysis for Identifying Causal Chains in Configurational Data: A Methodological Commentary on Baumgartner and Epple (2014). Sociol. Methods. Res. 2015, $44,723-736$. 
41. Thoms B (2011) A Dynamic Social Feedback System to Support Learning and Social Interaction in Higher Education. IEEE Trans Learn Technol 4:340-352

42. Toleikyte A (2018) Kranzl. L. and Müller.A. Cost curves of energy efficiency investments in buildings - methodologies and a case study of Lithuania. Energy Policy 115:148-157

43. Tuominen P, Klobut $K$, Tolman A (2012) Energy savings potential in buildings and overcoming market barriers in member states of the European Union. Energ Buildings 51:48-55

44. Harvey VorsatzD.Mirasgedis LD, Mark D (2007) Mitigating $\mathrm{CO}_{2}$ emissions from energy use in the world's buildings. Build 35:379-398 R Inf,

45. Wong. I.L. and kruger.E. Comparing energy efficiency labelling systems in the EU and Brazil: Implications, challenges, barriers and opportunities. Energy Policy 2017, 109, 365-382.

46. Wu. C, and Barnes. D. A dynamic feedback model for partner selection in agile supply chains. Int. J. Oper. Prod. Manage. 2012, 32, 79-103.

\section{Figures}

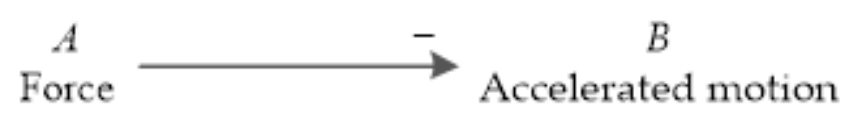

(a)

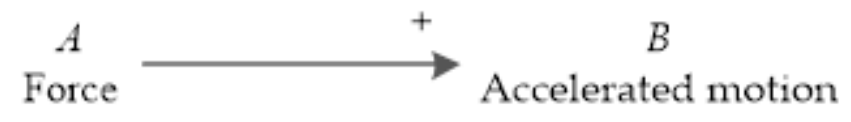

(b)

\section{Figure 1}

(a) Negative causal chain; (b) Positive causal chain

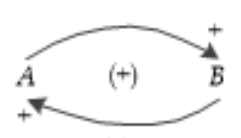

(a)

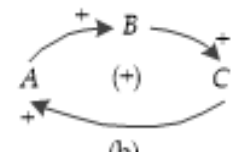

(b)

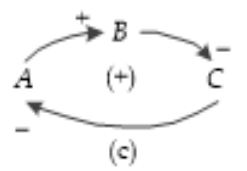

(c)

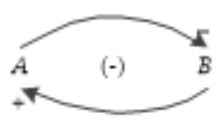

(a)

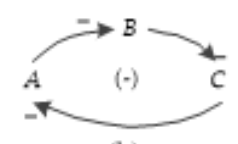

(b)

(b)

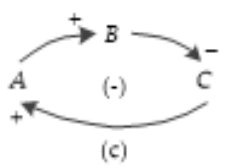

(c)

(a)

Figure 2

(a) Positive causal loop; (b) Negative causal loop 


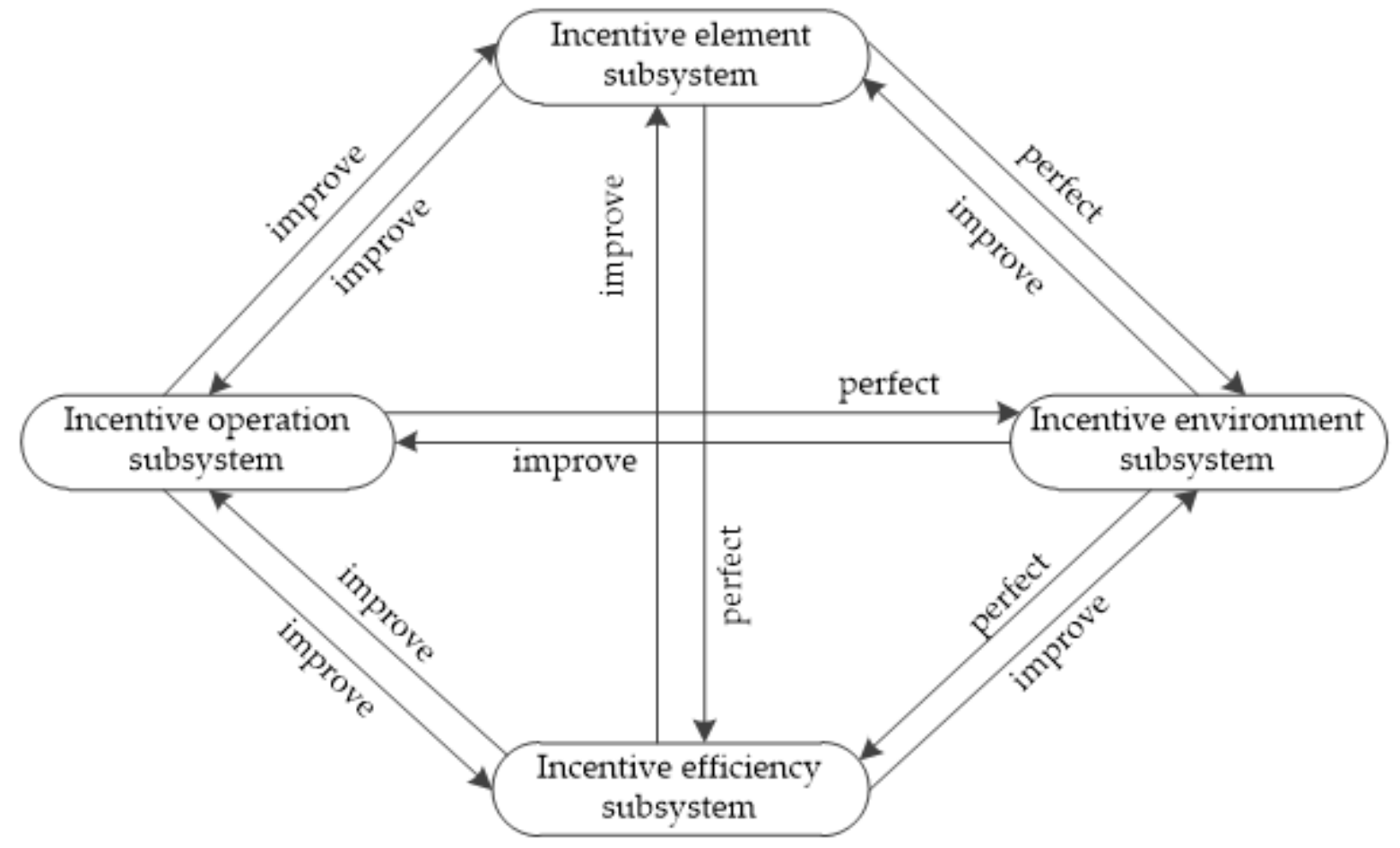

Figure 3

The structural framework of incentives total system

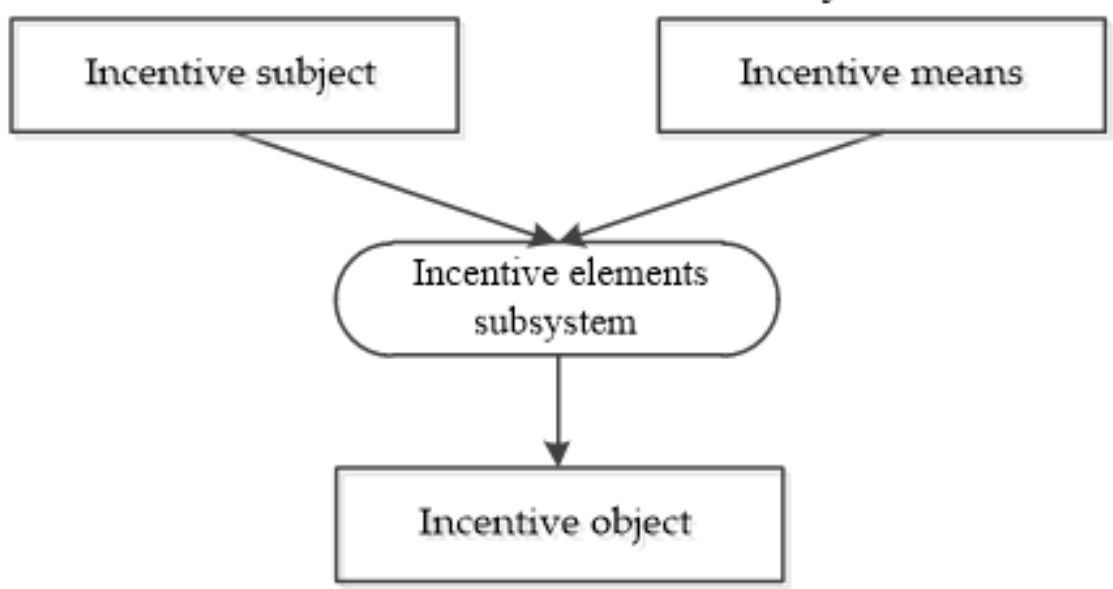

Figure 4

Structural of incentive elements subsystem 


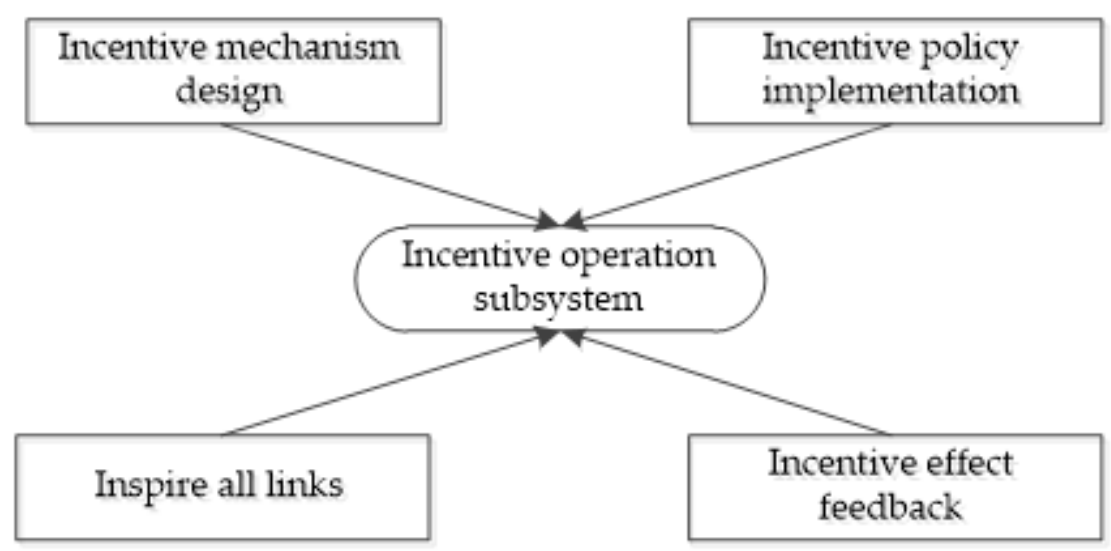

\section{Figure 5}

Structural of incentive operation subsystem

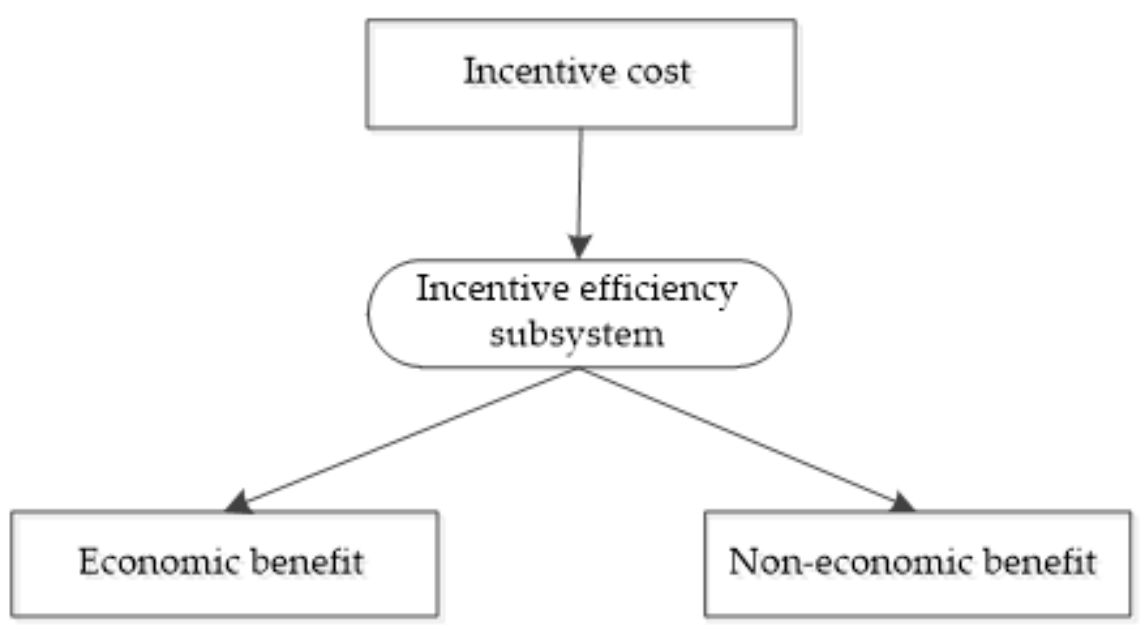

Figure 6

Structural of incentive efficiency subsystem

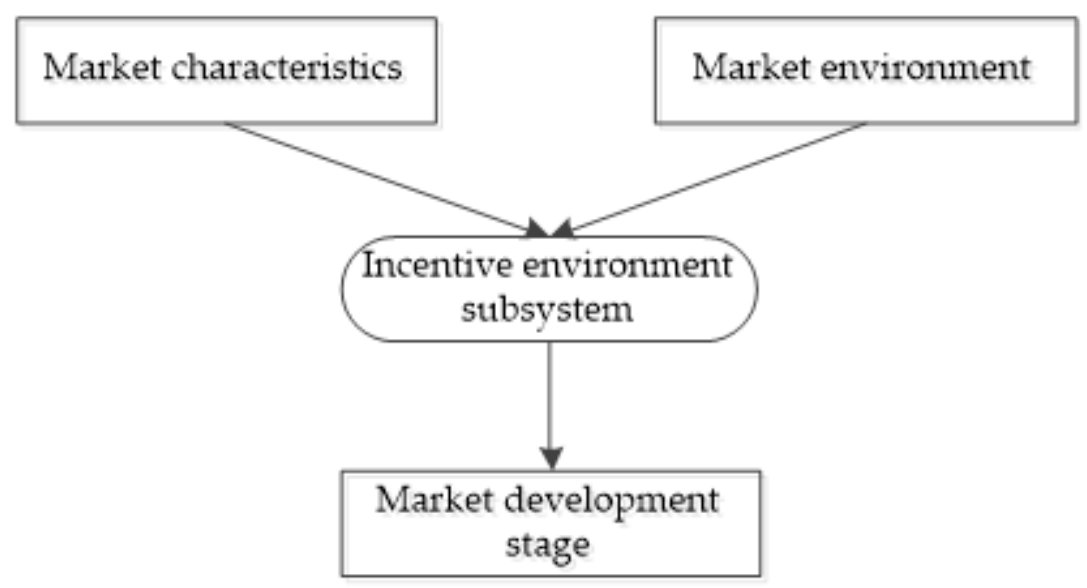

Figure 7 


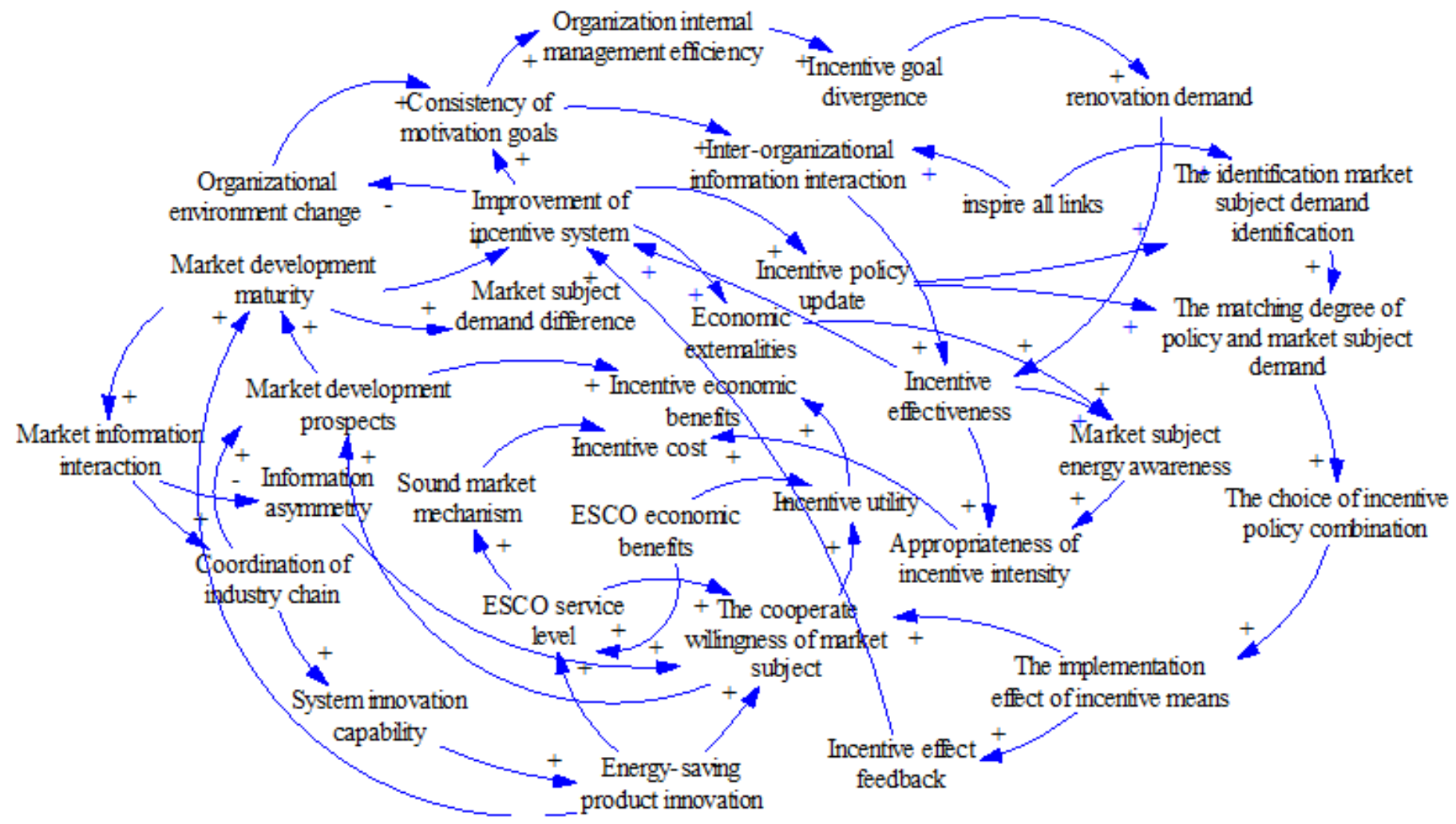

\section{Figure 8}

Causality of incentives total system 


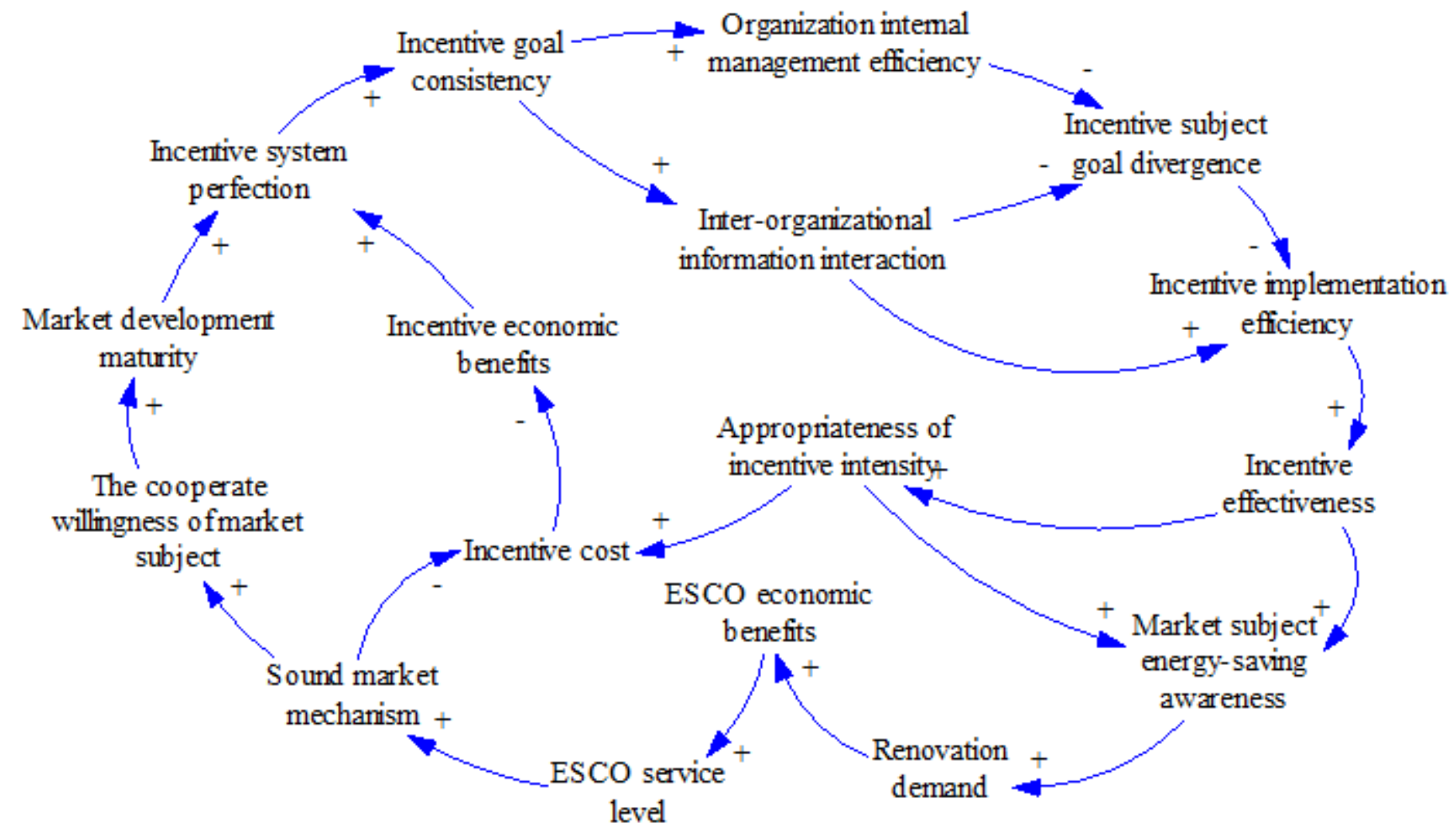

Figure 9

Causality of incentive elements subsystem

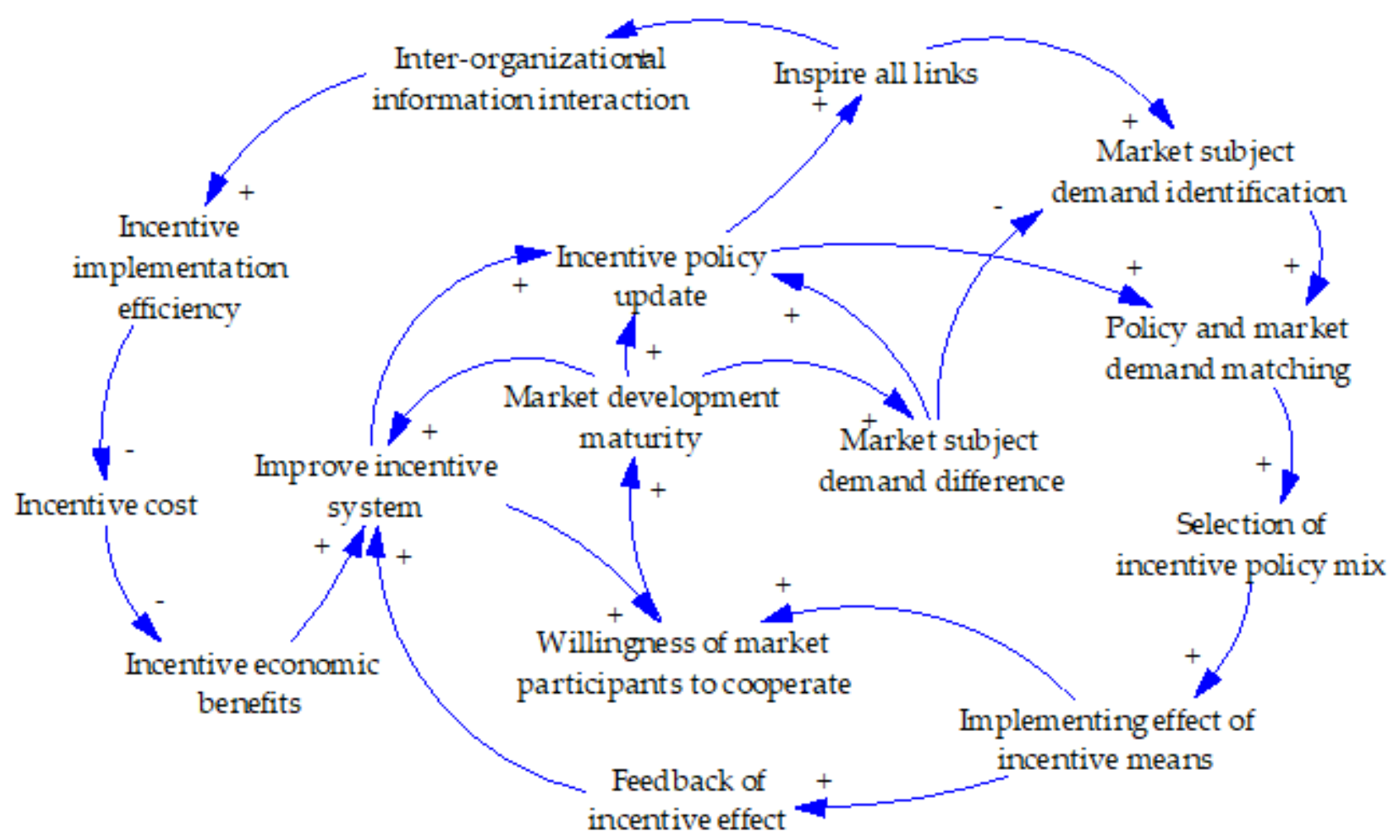


Figure 10

Causality of incentive operation subsystem

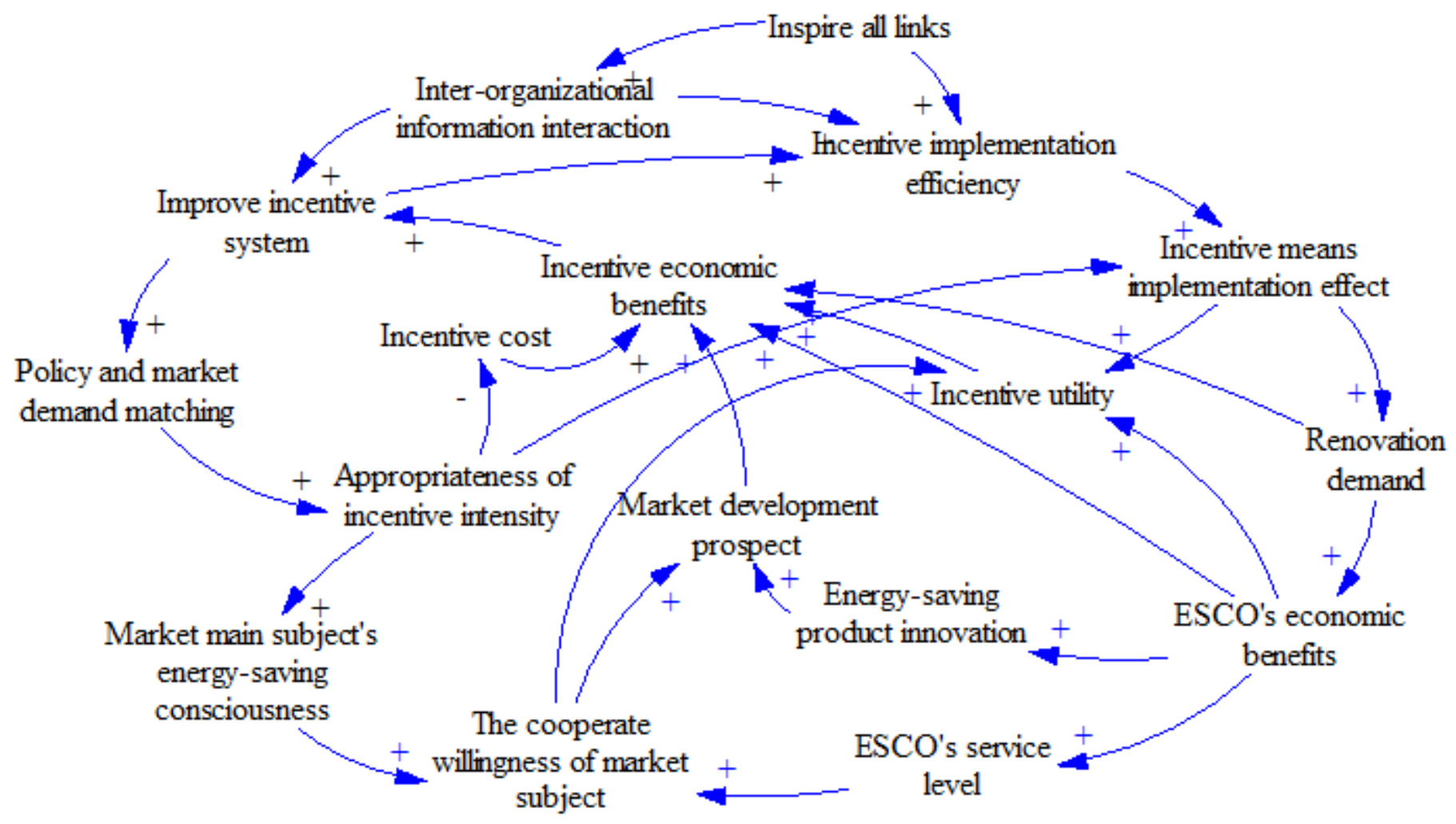

\section{Figure 11}

Causality of incentive efficiency subsystem 


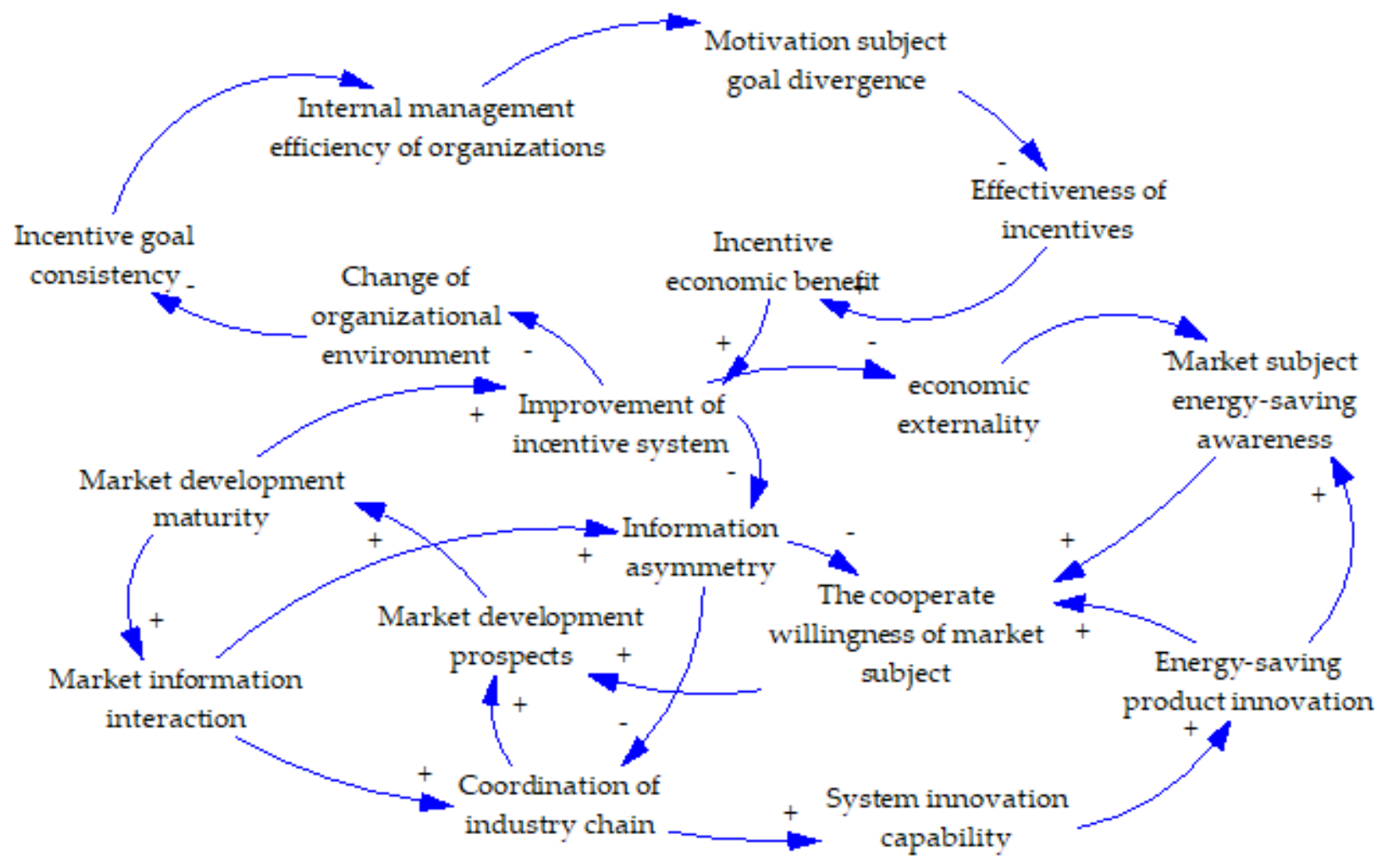

Figure 12

Causality of incentive environment subsystem 